\title{
Evaluating air pollution exposures across cycling infrastructure types: Implications for facility design
}

\author{
William J. Farrell \\ McGill University \\ william.farrell@mail.mcgill.ca \\ Mark Goldberg \\ McGill University \\ mark.goldberg@mail.mcgill.ca
}

\author{
Scott Weichenthal \\ McGill University \\ scott.weichenthal@mail.mcgill.ca \\ Marianne Hatzopoulou \\ McGill University \\ marianne.hatzopoulou@mail.mcgill.ca
}

Abstract: Expanding urban cycling networks requires consideration of a number of important factors. Yet there exists no set of best practices and surprisingly little research detailing which sorts of cycling infrastructure may be better or worse in terms of exposure to harmful pollutants. A large air-quality data collection campaign was conducted in summer 2012 whereby cyclists equipped with ultrafine particle (UFP) and black carbon (BC) monitors covered over 550 kilometers of streets, including 325 kilometers of designated cycling facilities on the Island of Montreal. The clearest result from this exercise is that pollution levels on trails, often far from vehicular streets, are markedly lower than cycling facilities located on or alongside the street. For in-street and separated facilities, both UFP and BC were more closely associated with the hierarchy of the street than the type of cycling facility. Between in-street and separated facilities, the difference in UFP levels was not statistically significant. However, the difference between BC levels on in-street and separated facilities was significant, with separated facilities yielding lower concentrations. Ultimately, more research is needed to understand the potential efficacy of facility and network design as a pollution exposure abatement measure; however, these findings show moderate advantages of separated facilities over in-street facilities and more substantial advantages for off-road facilities over either.

Keywords: ultrafine particles, black carbon, cycling infrastructure, cycling facilities, pollution exposure, cyclist exposure, environmental monitoring

\section{Article history:}

Received: December 10, 2013

Accepted: November 11, 2014

Available online: May 29, 2015

Copyright 2015 William J. Farrell, Scott Weichenthal, Mark Goldberg, \& Marianna Hatzopoulou http://dx.doi.org/10.5198/jtlu.2015.702

ISSN: 1938-7849 | Licensed under the Creative Commons Attribution - Noncommercial License 3.0

The Journal of Transport and Land Use is the official journal of the World Society for Transport and Land Use (WSTLUR) and is published and sponsored by the University of Minnesota Center for Transportation Studies. This paper is also published with sponsorship from WSTLUR and the Institutes of Transportation Studies at the University of California, Davis, and the University of California, Berkeley. 


\section{Introduction}

Traffic-related air pollution has a large impact on the health of urban populations. There is sufficient evidence to conclude that chronic exposure to ambient air pollution is associated with the incidence and mortality from cardiovascular disease, especially ischemic heart disease, and from lung cancer (Brook et al. 2004; Chen, Goldberg, and Villeneuve 2008). As well, there are overwhelming data implicating acute exposures to air pollution causing a variety of immediate health effects (Pope 2000; Dockery 2001; Pope and Dockery 2006). There is no escape from air pollution, especially in large urban areas, although there are small-scale variations that depend on traffic, land use, and other factors.

Recent research shows a strong association between the built environment and physical activity, suggesting that compact urban areas contribute to decreased automobile dependency and increased walking and cycling (Frank et al. 2007, 2008). Cycling is an increasingly popular choice for urban residents in North America, and cities are accordingly expanding their cycling infrastructure to accommodate this demand. However, planning an effective cycling network is a difficult task, demanding consideration of a large number of factors. Safety, comfort, accessibility, demand, cost, and maintenance must all be paid due attention, and all have been studied much in the literature and in practice. Yet there is a startling dearth of literature seeking to determine a set of best practices for designing cycling networks with respect to cyclists' exposure to harmful pollutants. Due to their proximity to traffic, high respiration rates, and longer journeys, cyclists are at risk of being exposed to higher concentrations of air pollution compared to other users of the road system.

Currently the research team is conducting a three-year research project in the city of Montreal. The overall goals of the project include the provision of essential information to develop innovative policies and guidelines to better design cycling infrastructure and information systems that will assist in minimizing exposure to air pollution among cyclists and other road users. The data collection campaign outlined in this paper constitutes the first objective, which is to identify factors affecting air pollution exposure based on characteristics such as cycling facility type, traffic, built environment, and meteorology, incorporating a wide survey of air pollution levels across Montreal roads. Future research will attempt to measure the acute health effects of this air pollution.

In this exercise, air pollution concentrations were collected along approximately 550 kilometers of roads in Montreal by cyclists equipped with global positioning system (GPS) devices and air pollution sampling instruments. This paper focuses specifically on exploring the relationship between traffic volume, cycling facility type, and concentrations of two pollutants: ultrafine particles (UFP) and black carbon (BC). The ultimate aim of the first project objective is to develop statistical models that capture the many determinants of cyclist exposure beyond traffic volumes and cycling facility type, such as land use and meteorology.

\section{$2 \quad$ Air polution and urban cycling}

Air pollution, including particulate matter (PM), has long been known to cause negative health outcomes, such as increased mortality and morbidity (Samet et al. 2000; Katsouyanni et al. 2001; Brunekreef and Holgate 2002). PM10, or PM with a diameter of less than $10 \mu \mathrm{m}$, can enter the lower respiratory system while PM2.5 can enter the gas-exchange regions of the lungs (Brunekreef and Holgate 2002). More recently, two forms of PM, ultrafine particles (UFP) and black carbon (BC), have been the subjects of much research.

UFP is an order of magnitude smaller than PM2.5, with a maximum diameter of $0.1 \mu \mathrm{m}$, while its total surface area is up to 1000 times greater per unit mass than PM2.5 (Berghmans et al. 2009). Its size implies that it can infiltrate much more deeply into the lungs and lung tissue and its surface area implies 
more interaction with the tissue at the cellular level. Because of these factors, it has been suggested that conventional environmental monitoring measures accounting only for PM mass are insufficient to fully understand personal PM exposure (Martins et al. 2010). UFP has been linked to a number of negative acute and chronic health outcomes, among them oxidative-stress induced DNA damage (Li et al. 2002; Calderón-Garcidueñas et al. 2008), reduced heart rate variability (Weichenthal et al. 2011), deposition of particles in the lungs (Int Panis et al. 2010), and inflammation of the cardiovascular and respiratory systems (Card et al. 2008; Jacobs et al. 2010; Strak et al. 2010). BC, also known as soot, is primarily caused by diesel traffic and is known to contribute to anthropogenic climate change. It too is linked to cardiovascular and respiratory inflammation (Jansen et al. 2005; Highwood and Kinnersley 2006). BC and UFP are also associated with a decrease in peak expiratory flow rate (Zuurbier et al. 2011).

Both UFP and BC are associated with traffic emissions and therefore are elevated in near-road environments. Increasingly, these two pollutants are used as markers of traffic-related air pollution.

Near roadway air pollution is a problem affecting all users of the street, considering that travel accounts for a disproportionately large fraction of personal daily exposure to air pollution (de Nazelle et al. 2012; Dons et al. 2012). Research that investigates the interactions between the built environment, active transportation, and air quality has focused on monitoring personal exposure in transport micro-environments, showing air pollution exposure to be elevated not only for pedestrians and cyclists but also for drivers and transit riders. Briggs et al. (2008) showed that mean exposures while walking were greatly in excess of those while driving. Tsai et al. (2008) found that motorcycle commuters were exposed to the highest concentrations and car commuters to the lowest, while bus commuters' longer commuting time resulted in high exposures. In a review of personal exposure studies, Kaur, Nieuwenhuijsen, and Colvile (2007) noted that most studies found higher in-vehicle exposures compared to pedestrians. Indeed, the vast majority of research is converging on the understanding that air pollution exposure levels are greater in motorized vehicles than in active modes of transport for UFP (Boogaard et al. 2009; Kaur and Nieuwenhuijsen 2009; de Nazelle et al. 2012; Kingham et al. 2013), BC (Highwood and Kinnersley 2006; de Nazelle et al. 2012; Dons et al. 2012), and a number of other pollutants.

There are many reasons for the differences in research findings, namely variations in the environmental context, monitoring methods, meteorology, vehicle ventilation, and most importantly, exposure duration and breathing rates, which have not been consistently taken into account. Due to the nature of cycling, and to a lesser extent, walking, personal dosage for the same level of exposure for both UFP (Berghmans et al. 2009; Int Panis et al. 2010; de Nazelle et al. 2012) and BC (de Nazelle et al. 2012; Dons et al. 2012) may be up to twice as high during active transportation. This is primarily due to increased minute ventilation of cyclists, which could be over four times as high compared with drivers and passengers of motorized transportation (Int Panis et al. 2010).

Despite this evidence, the promotion of cycling facilities and development of cycling networks is done with little regard to cyclists' exposure to air pollution. However, a number of studies are beginning to emerge highlighting the effect that route choice has on pollution exposure. Streets with higher traffic volumes are associated with higher UFP (Boogaard et al. 2009; Kaur and Nieuwenhuijsen 2009; Kingham et al. 2013) and BC (Dons et al. 2013). Research that assesses the factors affecting overall exposure found that traffic density and dispersion characteristics of the road (Briggs et al. 2008), pavement position, and the side of road walked upon (Kaur, Nieuwenhuijsen, and Colvile 2005), as well as traffic volumes, wind speed, and operation of the clearway (Greaves, Issarayangyun, and Liu 2008) as significant predictors of exposure.

Regarding the actual facility type, very little research has been conducted, and without decisive results. One study has shown that more popular cycling routes were characterized by higher exposure to NO2, a common marker of traffic-related air pollution, based on a land-use regression model (Strauss 
et al. 2012). Some very recent studies have shown that physically separated cycling facilities may in fact have a modest reduction of UFP (Hatzopoulou et al. 2013; Kingham et al. 2013) and BC (Hatzopoulou et al. 2013) concentrations. The manipulation of natural pollutant dispersion patterns in urban street canyons - known as passive control of air emissions - through low boundary walls (McNabola, Broderick, and Gill 2008), trees (Buccolieri et al. 2009), and noise barriers (King, Murphy, and McNabola 2009) has shown promising results. Note, however, that under certain conditions passive controls have been shown to significantly increase concentrations on the roadway (Baldauf et al. 2008).

This study attempts to expand on previous findings in order to strengthen our understanding of the role that cycling infrastructure plays in cyclists' exposure to pollution.

\section{$3 \quad$ Methodology}

\subsection{Data collection}

The study was conducted over 23 weekdays during the months of June and July 2012 on the Island of Montreal, Quebec, Canada. It consisted of two pairs of research assistants each cycling one of 25 pre-defined routes. Each route was a circuit of approximately 25 kilometers in length and was charted with an effort to include as many designated cycling facilities as possible in a diverse array of microenvironments. In total, approximately 550 kilometers of unique roadways were covered, including over 325 kilometers of designated cycling facilities (Figure 1). Each route was measured during two time periods: at approximately $8 \mathrm{a} . \mathrm{m}$. and 4:30 p.m. Trips—defined as a pair of research assistants completing a single route during a single time period-were typically completed within two hours. Fifteen routes began at a single location in downtown Montreal and 10 began in five different locations in surrounding towns and boroughs on the island. Trips originating downtown were typically measured twice per day on at least two different days. Trips originating in the peripheral regions were measured twice on a single

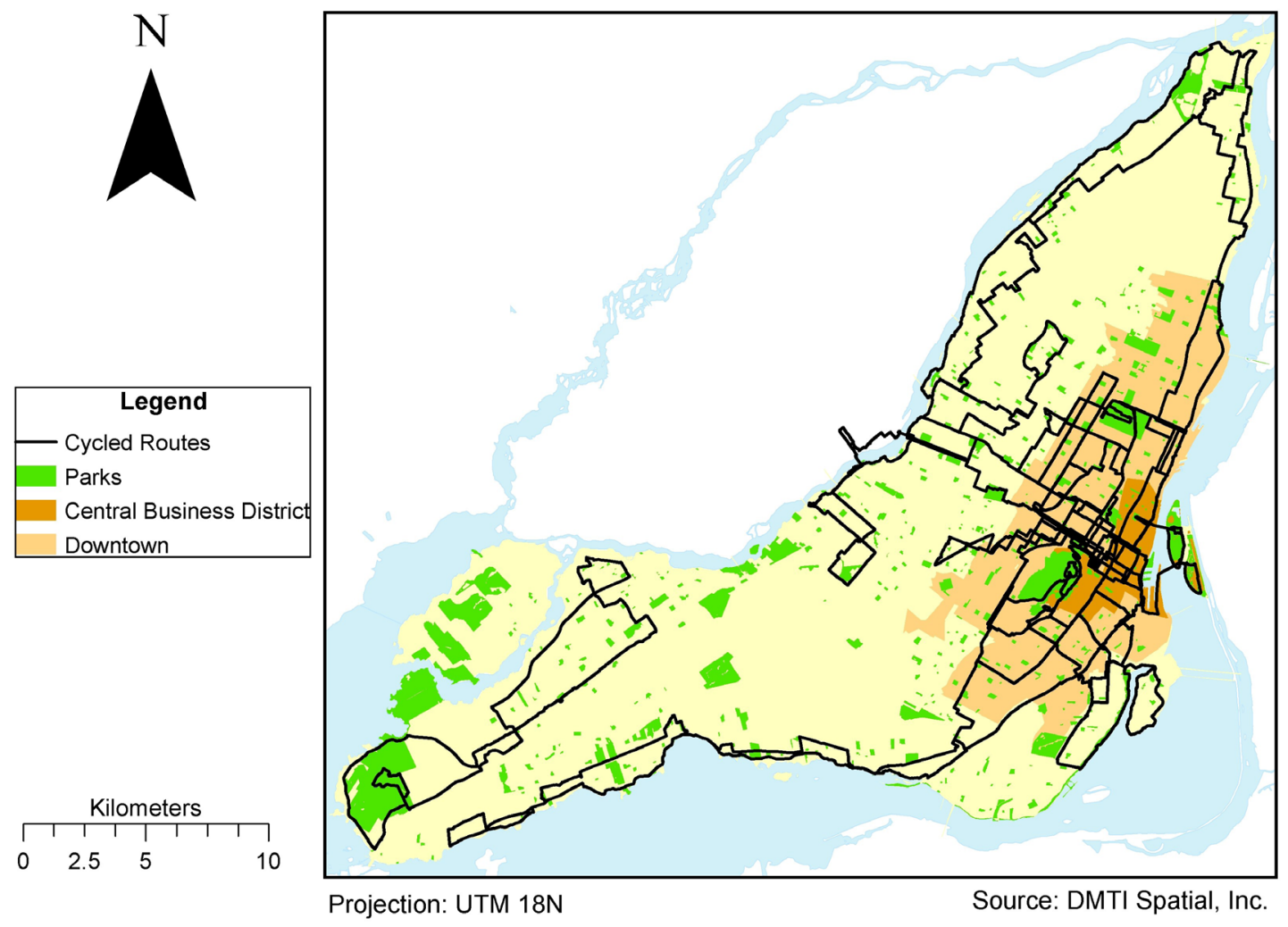

Figure 1: The extent of the cycled network, shown with parks, the central business district, and what is defined as the Montreal downtown area 
day, save for two peripheral routes, which were measured only once in the afternoon due to inclement weather, and could not be re-scheduled. In total approximately 2000 kilometers of measurements were recorded (Table 1).

Four project bicycles were used, each equipped with a number of instruments. All four bicycles carried a condensation particle counter (TSI, CPC Model 3007) to measure the total number of suspended particles per cubic centimeter $(\# / \mathrm{cm} 3)$, which are overwhelmingly comprised of UFP. Three bicycles also carried a microaethelometer (Magee Scientific, MicroAeth AE51) to measure BC (ng/m3) in a pannier above the rear wheel. The instruments were connected to a hose that ran along the frame of the bicycle to the handlebar, near the respiration zone of the cyclist. All four bicycles also carried a GPS unit (Garmin, Edge 800) to relate air-quality data with its measured coordinate and to help navigate the route to be measured. All instrument clocks were synchronized with a central computer prior to each trip and measurements were recorded at a frequency of $1 \mathrm{~Hz}$. In total, over 213 hours of real-time measurements were recorded.

Table 1: Route descriptions

\begin{tabular}{|l|r|r|r|}
\hline \multicolumn{1}{|c|}{ Trip Origin } & Number of Routes & Trips Recorded & Distance Measured (km) \\
\hline Downtown & 15 & 60 & 1537 \\
\hline SE suburb & 2 & 4 & 103 \\
\hline NE suburb & 2 & 4 & 97 \\
\hline N suburb & 2 & 4 & 98 \\
\hline NW suburb & 2 & 2 & 51 \\
\hline SW suburb & 2 & 4 & 98 \\
\hline TOTAL & $\mathbf{2 5}$ & $\mathbf{7 8}$ & $\mathbf{1 9 8 5}$ \\
\hline
\end{tabular}

In addition to air quality data, meteorological and road network information were also obtained. Realtime temperature data were recorded by the GPS unit while wind speed and relative humidity were obtained at the hourly level from the nearer of two Environment Canada (EC) meteorological stations on the Island of Montreal. Road hierarchies were obtained from a geographic information system (GIS) representation of the street network (DMTI Spatial, Inc.), which included both motorized streets and non-motorized trails. This GIS data was also used to produce vehicular volumes, which were obtained from a mesoscopic traffic simulation model previously developed by the research team (Sider et al. 2013). The model results have been validated against traffic counts across Montreal; we observe a correlation of 0.78 between measured and modeled values. A GIS representation of cycling facilities was also obtained from the city of Montreal, which included seven facility types, as defined by the city, ranging from shared street to multi-use trail.

\subsection{Data processing}

All air-quality data were merged with their respective GPS coordinates and compiled into a single database. Data were excluded if they did not contain at least one air quality measurement or if there was no associated coordinate. In some cases of instrument malfunction, the partner's GPS coordinates were used, considering their close proximity to one another during their trip. Figure 2 illustrates how pointlevel data obtained from merging GPS and air pollution readings were related to the road and cycling networks.

Due to vibration-induced noise in the readings of the microaethelometer during cycling, the optimized noise averaging (ONA) technique was used to smooth peaks and remove negative values (Hagler 2011). Briefly, the microaethelometer measures BC using an optical sensor; this technique averages 
values over light attenuations of 0.05 , resulting in a median averaging of 1.5 minutes for this dataset. These average values were assigned to the original GPS coordinate.

All data points were related to the motorized roadway that the cyclists were riding either on or alongside based on the initial identification of cycling routes (Figure 2). If no street could be reasonably related to the point, for instance within parks, the nearest roadway link was selected. Points were also related with a non-motorized trail if it was ridden on or alongside, within 15 meters. Finally, data points within 15 meters of a cycling facility were assigned those attributes. If a point could not be associated with either a motorized roadway, trail, or cycling facility within 15 meters, it was not considered in this analysis.

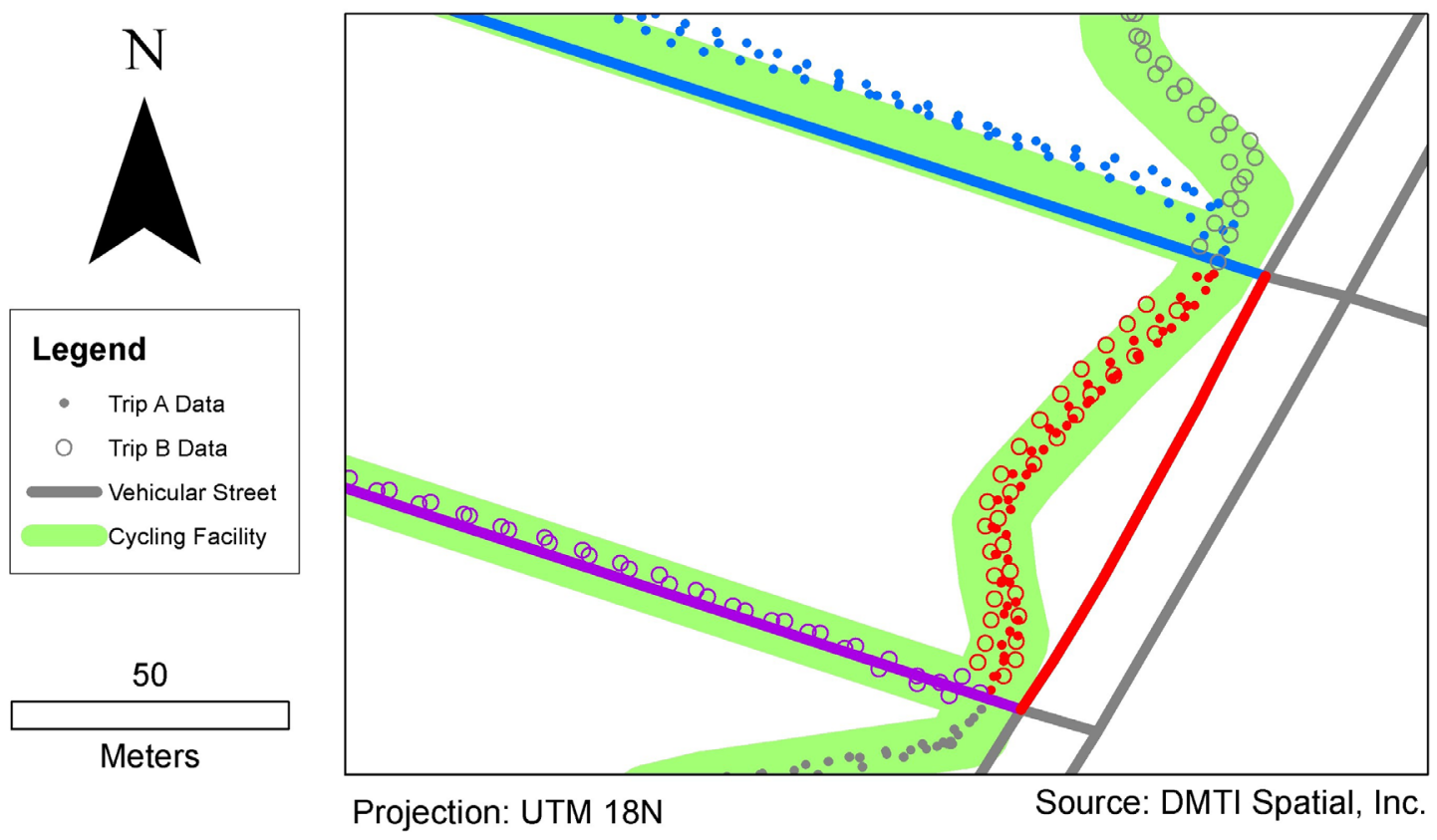

Figure 2: Data were averaged by each trip on each link; for example, the red solid circles and hollow circles were both averaged onto the red link but as two independent observations. All point data were also assigned the properties of the cycling facility (green) that they were cycled on.

The properties of all data points were averaged onto the nearest roadway or trail link per each trip. That is to say, each cycling trip on each link was treated as an independent observation. Properties included the road hierarchy classification and traffic volumes of the nearest motorized roadway and associated cycling facility properties if they fell within 15 meters of the point. This process resulted in a total of 17,775 independent observations, including 17,516 for UFP and 13,335 for BC. Each link was covered by a median of four trips. However, some links were covered only once, and links near the downtown origin were covered up to 60 times.

The seven designated cycling facility types were amalgamated based on similar characteristics into three functional categories, shown in Table 2. Shared streets, painted lanes, and roadways where no cycling infrastructure was present within 15 meters of the point of measurement were classified as "instreet." "Separated" facilities include cycle tracks, typically a bi-directional within the right-of-way of the street. These were usually separated by a concrete curb, bollards, or parked cars. Also included in this classification were facilities running alongside the roadway, separated by a grass median, thus further increasing the distance between the cyclists' path and the roadway. The third classification considered is comprised of multi-use trails, which are typically located within parks and at substantial distances from 
the roadway. Some trails are officially designated as cycling facilities; however, data points that were nearest to undesignated trails and not within 15 meters of a motorized roadway or an officially designated cycling facility were also included in this category.

Table 2: Designated and functional classification of cycling facilities

\begin{tabular}{|c|c|c|c|}
\hline \multicolumn{2}{|r|}{ City Designation } & \multicolumn{2}{|c|}{ Funcional Classification } \\
\hline 0 & (No designation) & \multirow{4}{*}{1} & \multirow{4}{*}{ In-street } \\
\hline 1 & Shared street & & \\
\hline 2 & Bicycle lane and shared street & & \\
\hline 3 & Bicycle lane & & \\
\hline 4 & On-street cycle track & \multirow{3}{*}{2} & \multirow{3}{*}{ Separated } \\
\hline 5 & Off-street cycle track & & \\
\hline 6 & Sidewalk-level cycle track & & \\
\hline 7 & Multi-use trail & 3 & Trail \\
\hline
\end{tabular}

Finally, to distinguish the effects of the cycling facilities from that of traffic volumes of the road, the road hierarchy was considered for each facility type. Local roads were considered as one category and all highways, arterials, and collectors were considered "major" roads. Since these data were related at the point level, categorical and dummy variables were rounded to the nearest integer following the averaging process described earlier. In total, 4356 links were measured (556 kilometers), including 2607 links categorized as "in street" (294 kilometers); 1597 links as "separated" (231 kilometers); and 152 links as "trail" (31 kilometers).

\section{$4 \quad$ Results}

\subsection{Air pollution mapping}

UFP (Figure 3) and BC (Figure 4) levels collected in the morning peak period and averaged over each link are illustrated below. Through visual inspection of the two maps, we observe significant spatial variability in the data collected.

All-day downtown UFP levels range between 3511 and 192,340 and BC levels range between 18 and 186,528 (Table 3). For the purposes of this study, "downtown" was defined as the central business district and all towns and boroughs adjacent to it (Figure 1). Figure 5 illustrates the frequency distributions of UFP and BC levels recorded throughout the day.

One thing to note is that morning UFP and $\mathrm{BC}$ readings are higher than afternoon readings (Table 3). This is due primarily to their inverse relationship to temperature and wind speed, both of which are lower in the morning. This affects the mixing height and atmospheric stability. While there is no health standard for UFP, mean concentrations typically observed in urban areas range between 6000 and 60,000 particles/cm3 (Wang et al. 2011). The concentration map presented in Figure 3 clearly shows that the majority of roads in Montreal experience levels within this range. 


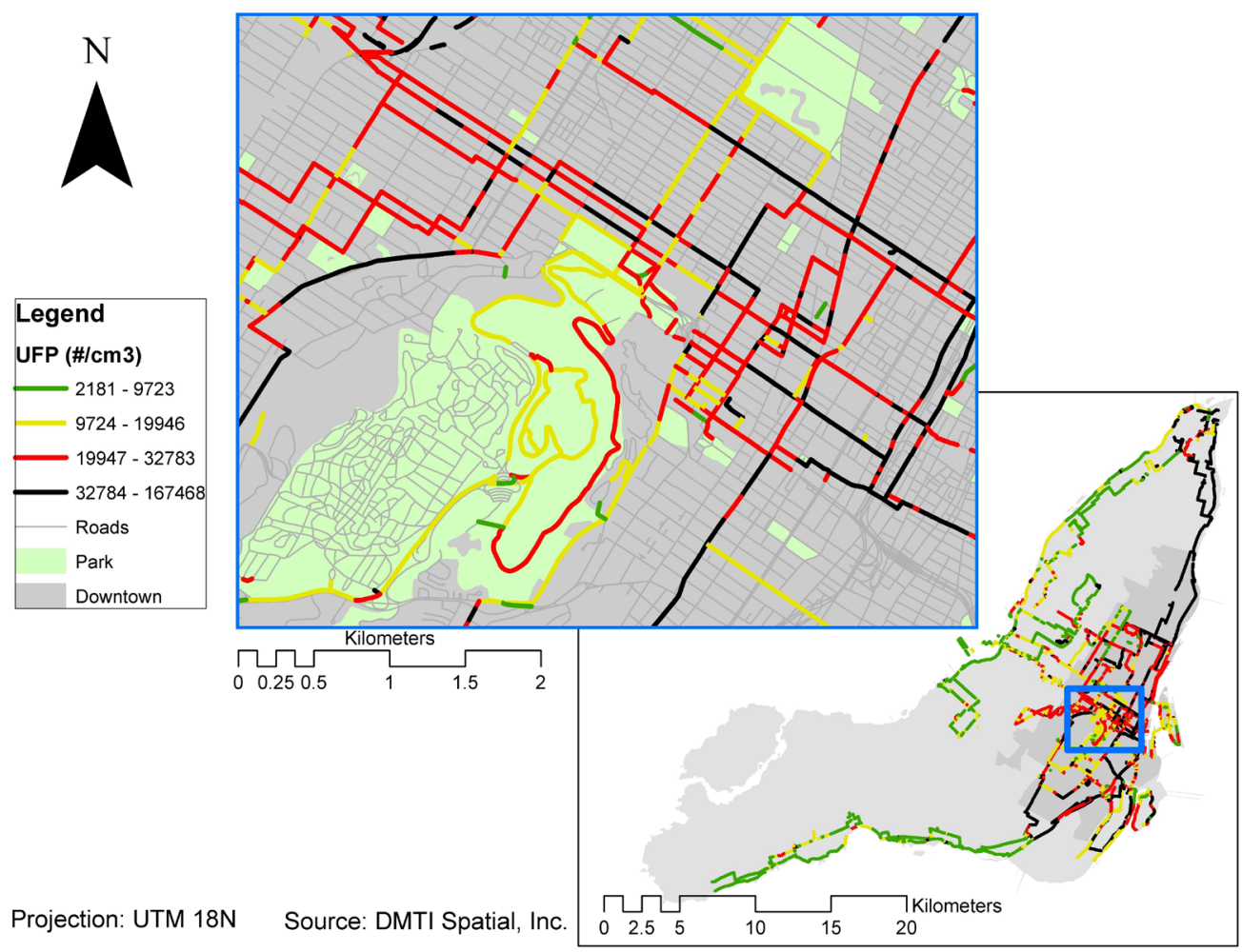

Figure 3: UFP concentration maps for the morning period, divided by quartiles; the link results shown are the average of all trips on the link.

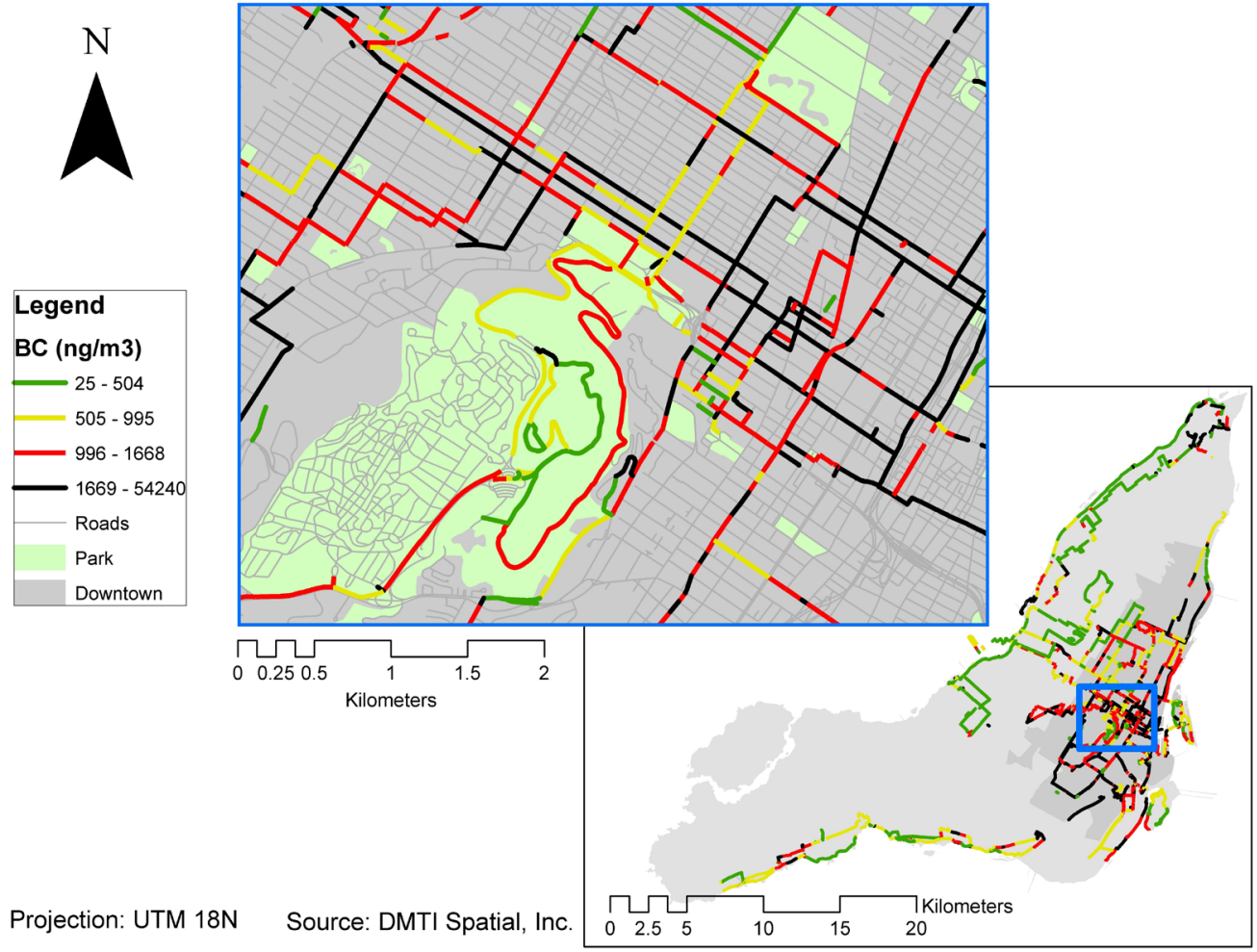

Figure 4: $\mathrm{BC}$ concentration maps for the morning period, divided by quartiles; the link results shown are the average of all trips on the link. 
Table 3: Air pollution variability

\begin{tabular}{|l|r|r|r|r|r|r|r|r|}
\hline \multirow{2}{*}{ Attribute } & \multicolumn{4}{|c|}{ UFP $\left(\# \mathbf{c m}^{3}\right)$} & \multicolumn{4}{|c|}{ BC $\left(\mathbf{n g} / \mathbf{m}^{\mathbf{3}}\right)$} \\
\cline { 2 - 9 } & \multicolumn{1}{|c|}{$\mathbf{N}$} & \multicolumn{1}{c|}{ Min } & \multicolumn{1}{c|}{ Mean } & Max & \multicolumn{1}{c|}{ n } & \multicolumn{1}{c|}{ Min } & \multicolumn{1}{c|}{ Mean } & \multicolumn{1}{c|}{ Max } \\
\hline Downtown & 11,965 & 3511 & 23,451 & 192,340 & 9271 & 18 & 1481 & 186,528 \\
\hline Suburbs & 5551 & 1411 & 15,836 & 112,298 & 4064 & 23 & 855 & 92,425 \\
\hline Morning & 8483 & 2181 & 24,948 & 192,340 & 6759 & 24 & 1484 & 56,351 \\
\hline Afternoon & 9033 & 1411 & 17,382 & 189,087 & 6576 & 18 & 1091 & 186,528 \\
\hline
\end{tabular}

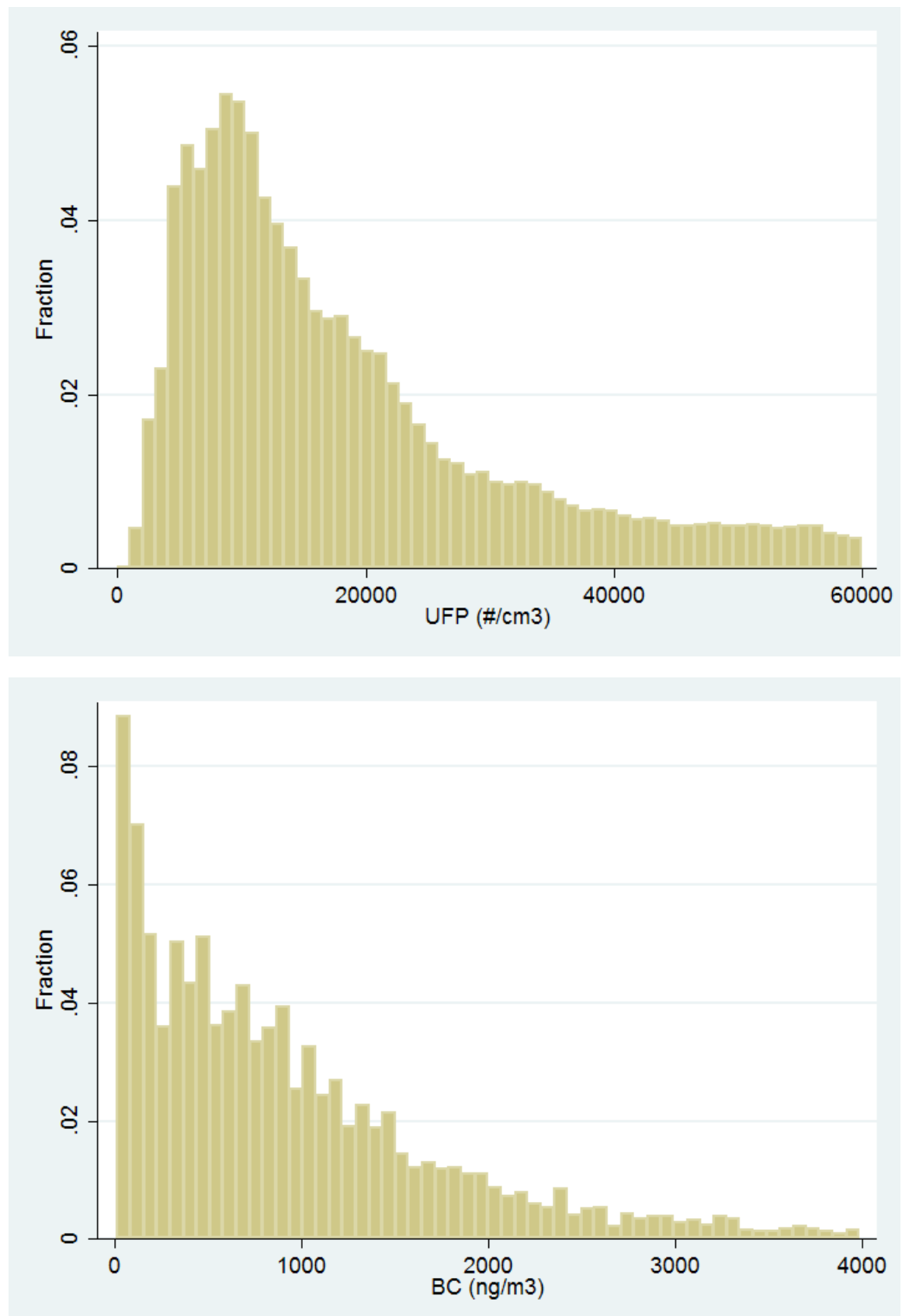

Figure 5: Histogram of UFP (L) and BC (R) distributions (omitting values > 95th percentile) 


\subsection{Cycling facilities analysis}

Air pollution results aggregated per cycling facility type are shown below in Table 4. The table shows the average UFP, BC, daily vehicular volume, and the median distance between the GPS points and the centerline of the nearest motorized roadway. Also shown are the relative differences in mean UFP and BC using their respective road hierarchy for "in-street" facilities as their baseline value.

Table 4: Pollution, traffic, and distance from road by cycling facility class

\begin{tabular}{|l|r|r|r|r|r|r|}
\hline \multirow{2}{*}{} & \multicolumn{2}{|c|}{ In-Street } & \multicolumn{2}{c|}{ Separated Track } & \multicolumn{2}{c|}{ Trail } \\
\cline { 2 - 7 } & Major & \multicolumn{1}{|c|}{ Local } & \multicolumn{1}{c|}{ Major } & \multicolumn{1}{c|}{ Local } & \multicolumn{1}{c|}{ Major } & \multicolumn{1}{c|}{ Local } \\
\hline Cycling facility classification & 0 & 1 & 2 & 3 & 4 & 5 \\
\hline Number of link-trips & 3665 & 7058 & 4017 & 2420 & 254 & 334 \\
\hline Total length (km) & 103 & 191 & 137 & 94 & 19 & 15 \\
\hline Mean UFP (\#/cm3) & 22,551 & 19,681 & 23,223 & 20,733 & 13,693 & 15,120 \\
\hline UFP \% change from baseline &. &. & $3 \%$ & $5 \%$ & $-41 \%$ & $-27 \%$ \\
\hline Minimum UFP & 1547 & 1411 & 1547 & 1798 & 3171 & 2856 \\
\hline Maximum UFP & 189,097 & 192,340 & 167,468 & 134,403 & 70,0619 & 77,125 \\
\hline Mean BC (ng/m3) & 1733 & 1133 & 1404 & 1063 & 687 & 638 \\
\hline BC \% change from baseline &. &. & $-19 \%$ & $-6 \%$ & $-51 \%$ & $-40 \%$ \\
\hline Minimum BC & 18 & 18 & 18 & 23 & 18 & 28 \\
\hline Maximum BC & 186,528 & 54,240 & 92,424 & 56,661 & 9900 & 6183 \\
\hline Daily traffic volume (veh) & 3660 & 1467 & 3848 & 1398 & 4383 & 1313 \\
\hline Median distance from road centerline (m) & 4.2 & 3.4 & 8.8 & 8.5 & 145.1 & 67.6 \\
\hline
\end{tabular}

A number of observations can be made based on the data presented in Table 4. First, despite trails having vehicular volumes approximately equal to or greater than the other two categories, both UFP and $\mathrm{BC}$ levels are notably lower than on the other two facility types. Of course, the median distances from the motorized roadway centerline are substantially greater than the other facilities, indicating that these pollutants may drastically decay at greater distances from the roadway. Also noteworthy is that between the in-street and separated facilities, the road hierarchy appears to play a stronger role than the actual facility type. In fact, comparing like road hierarchies, UFP levels are nearly identical between in-street and separated facilities, albeit with the latter slightly elevated. However, for $\mathrm{BC}$ there appears to be a larger reduction for separated facilities as compared to in-street. This may suggest that $\mathrm{BC}$ is more sensitive to the subtle difference in composition and distance from the roadway than UFP, perhaps due to settling caused by its larger particle size and weight. Still, the greater distances observed on trails seem to dominate the ultimate pollution level. Also of note is that when reductions are present, they appear to be greater on major roads than local ones. This suggests that there may be more to be gained by increasing the separation between cyclists and motorized traffic on these larger streets.

Understanding now the differences in volume and distance of the various facilities, a closer look at pollution levels is revealed by the box plots of UFP (Figure 6) and BC (Figure 7). Minimum pollution levels for both UFP and BC appear to be unaffected by facility type. Maximum and interquartile UFP levels also appear nearly identical for in-street and separated facilities. However, the differences for $\mathrm{BC}$ appear to be more substantial, where not only are the maximum concentrations lower, but the interquartile ranges also show conspicuously lower concentrations for separated facilities than in-street. Again, though, cycling trails, typically far from the motorized roadway, are clearly lower than their counterparts. 


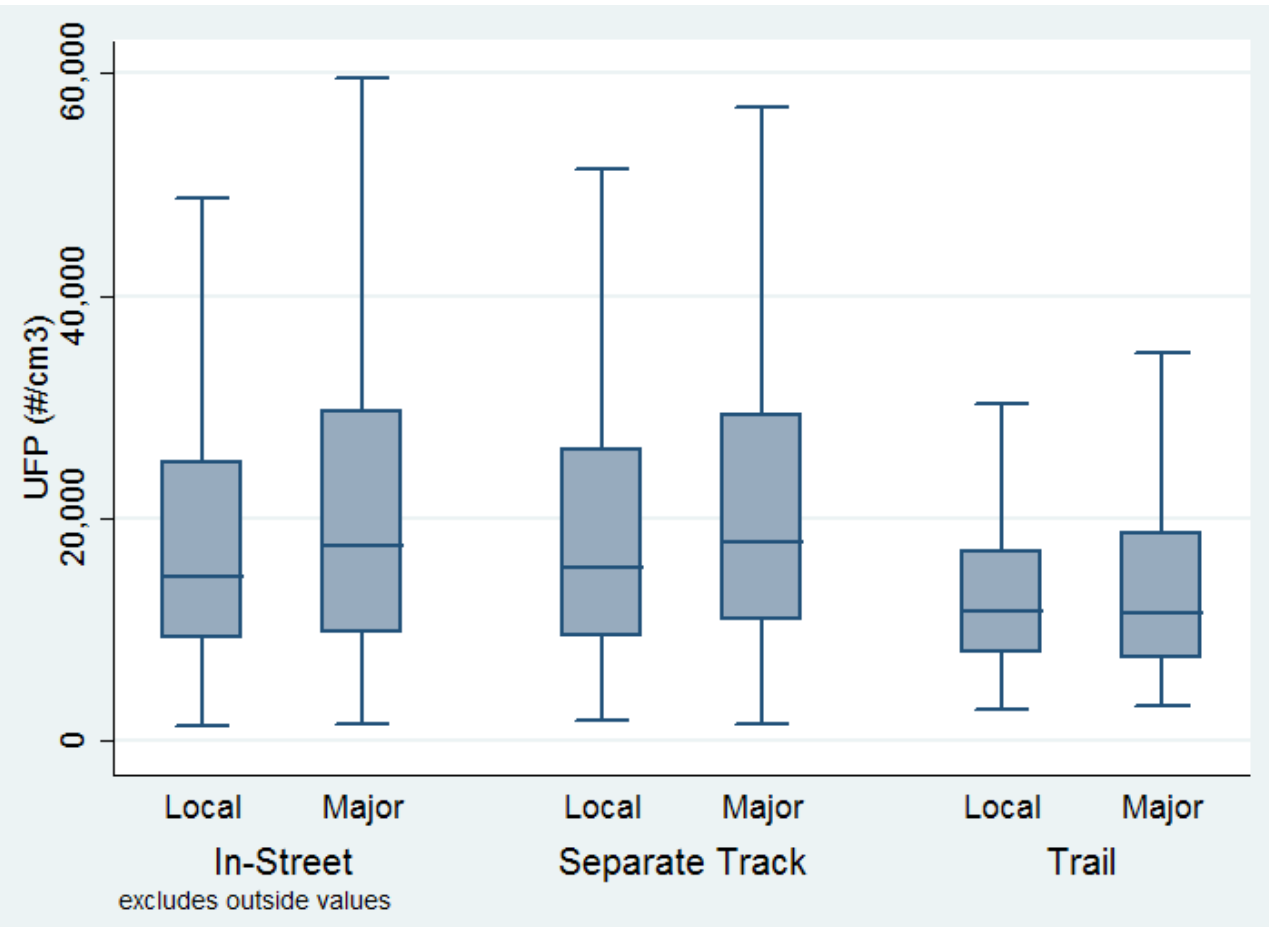

Figure 6: UFP box plot by cycling facility and road type (whiskers do not exceed $1.5 \mathrm{IQR}$ )

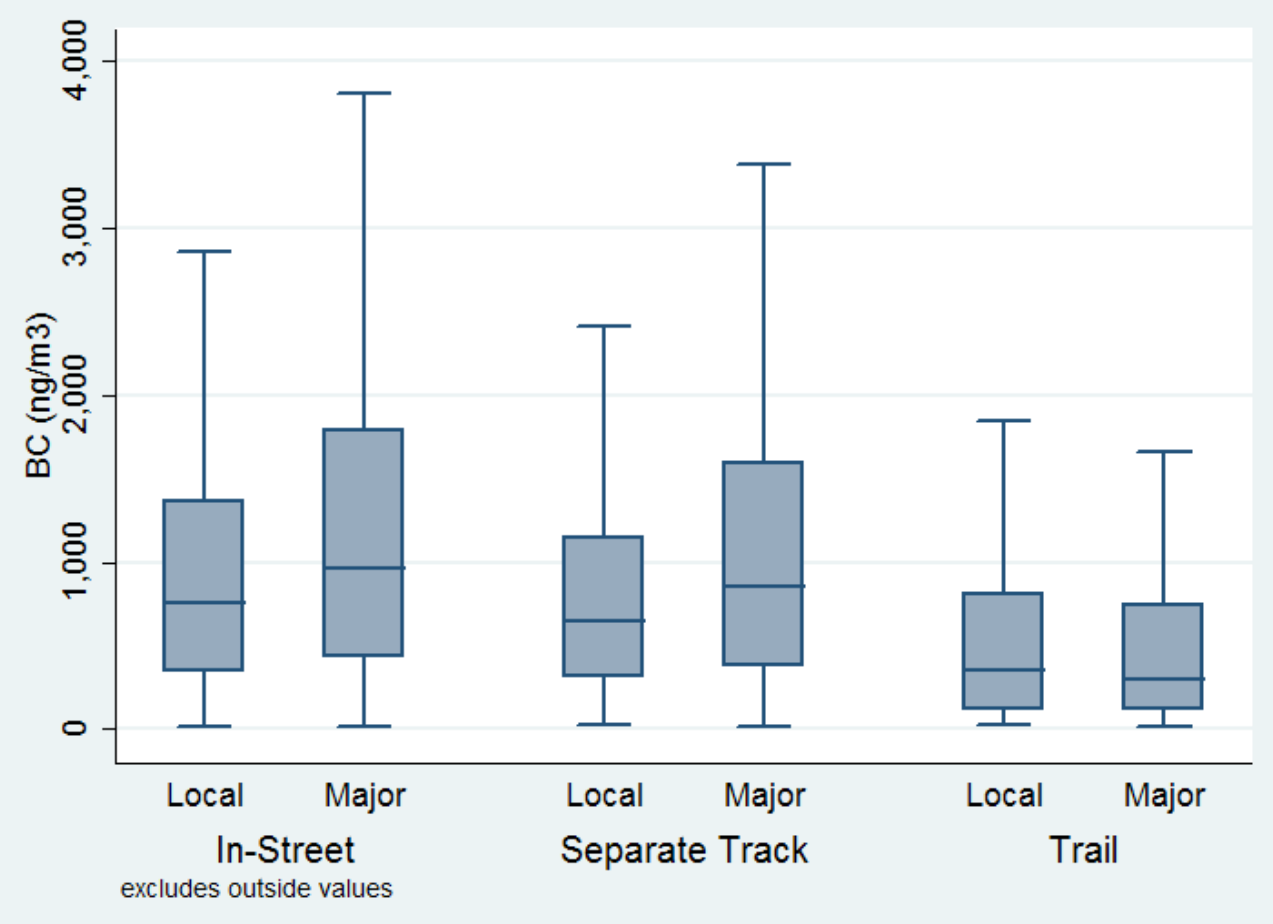

Figure 7: $\mathrm{BC}$ box plot by cycling facility and road type (whiskers do not exceed $1.5 \mathrm{IQR}$ ) 


\subsection{Regression analysis}

Finally, a regression analysis was conducted to obtain a more quantitative understanding of the interaction between the cycling facilities and road hierarchy. Dummy variables were included for relations with a major road, separated facility, and trail facility. Previous analysis of this dataset depicted the dominant effects of meteorology, so they were also included in the regression. Meteorological variables include a dummy variable for the real-time temperature being over $20^{\circ} \mathrm{C}$, and trip-level variables including the minimum temperature, wind speed, and relative humidity. Table 5 presents the variables considered for the regression analysis.

Regressions were performed with the natural logarithm transform of the dependent variables due to their log-normal distribution (Figure 5), and were subsequently sorted by relative effect, as determined by the magnitude of their normalized beta coefficient.

Table 5: Descriptive statistics for regression variables considered

\begin{tabular}{|l|l|r|r|r|}
\hline \multicolumn{1}{|c|}{ Variable } & \multicolumn{1}{c|}{ Units } & \multicolumn{1}{c|}{ Mean } & \multicolumn{1}{c|}{ Min } & \multicolumn{1}{c|}{ Max } \\
\hline Daily traffic volume & Vehicles & 2486.18 & 0.00 & 15,676 \\
\hline $\begin{array}{l}\text { Centerline distance from } \\
\text { motorized roadway }\end{array}$ & $\mathrm{m}$ & 16.02 & 0.04 & 687.57 \\
\hline Major road & Dummy & 0.45 & 0 & 1 \\
\hline Separated facility & Dummy & 0.36 & 0 & 1 \\
\hline Trail facility & Dummy & 0.03 & 0 & 1 \\
\hline Real-time temperature $\geq \mathbf{2 0}^{\circ} \mathbf{C}$ & Dummy & 0.85 & 0 & 1 \\
\hline Minimum trip temperature & ${ }^{\circ} \mathrm{C}$ & 20.00 & 13.00 & 34.00 \\
\hline Trip wind speed & $\mathrm{km} / \mathrm{hr}$ & 14.53 & 5.50 & 24.50 \\
\hline Trip relative humidity & $\%$ & 0.53 & 0.29 & 0.84 \\
\hline
\end{tabular}

The coefficients presented in Table 6 for UFP and Table 7 for BC illustrate the effects of meteorology, type of facility, and traffic on measured air pollution levels. It is important to note at the onset that these regressions are not meant to develop predictive models of UFP and BC in near-road environments. Clearly, land use and other road geometry variables affect the measured concentrations and are not included in the models. The main purpose of these regressions is to capture the simultaneous effects of traffic and bicycle facility design while adjusting for meteorology, therefore shedding light on the associations between air pollution and bicycle facilities.

The UFP regression in Table 6 shows more quantitatively what was earlier described. Cycling on a trail was associated with the strongest reductions of UFP levels, affecting concentrations even more than cycling on or alongside a major road. The dummy variable for separated facilities was included to show that they produced no additional significant difference for UFP concentrations. 
Table 6: Linear regression for $\operatorname{In}(\mathrm{UFP})(\mathrm{n}=17,516 ; \mathrm{R} 2=0.223)$

\begin{tabular}{|l|l|r|r|r|r|r|}
\hline \multicolumn{1}{|c|}{ Variable } & \multicolumn{1}{c|}{ Units } & Coefficient & \multicolumn{1}{c|}{ SE } & \multicolumn{1}{c|}{$\mathbf{c}$} & \multicolumn{1}{c|}{$\boldsymbol{P}>|\mathbf{t}|$} & \multicolumn{1}{c|}{$\boldsymbol{\beta}$} \\
\hline Minimum temperature & ${ }^{\circ} \mathrm{C}$ & -0.048 & 0.002 & -28.95 & 0.000 & -0.258 \\
\hline Wind speed & $\mathrm{km} / \mathrm{hr}$ & -0.027 & 0.001 & -27.51 & 0.000 & -0.197 \\
\hline Temperature $\geq \mathbf{2 0 ^ { \circ } \mathbf { C }}$ & Dummy & -0.325 & 0.017 & -18.69 & 0.000 & -0.156 \\
\hline Relative humidity & $\%$ & -0.767 & 0.041 & -18.59 & 0.000 & -0.127 \\
\hline Trail facility & Dummy & -0.413 & 0.028 & -14.56 & 0.000 & -0.098 \\
\hline Major road & Dummy & 0.090 & 0.010 & 8.60 & 0.000 & 0.060 \\
\hline Separated facility & Dummy & 0.008 & 0.011 & 0.71 & 0.476 & 0.005 \\
\hline Constant & & 11.739 & 0.040 & 293.60 & 0.000 & \\
\hline
\end{tabular}

Table 7, which shows the linear regression for BC, paints a slightly different picture. Here the effect of trails has shown to be even greater than some meteorological variables, and the effect of separated facilities appears to have a statistically significant effect on lowering BC concentrations. Again, this suggests that $\mathrm{BC}$ may be more sensitive to the distance from the roadway and other micro-environmental factors than UFP.

Table 7: Linear regression for $\operatorname{In}(\mathrm{BC})(\mathrm{n}=13,335 ; \mathrm{R} 2=0.153)$

\begin{tabular}{|l|l|r|r|r|r|r|}
\hline \multicolumn{1}{|c|}{ Variable } & \multicolumn{1}{c|}{ Units } & Coefficient & \multicolumn{1}{c|}{ SE } & \multicolumn{1}{c|}{$\mathbf{T}$} & \multicolumn{1}{c|}{$\mathbf{P}>|\mathbf{t}|$} & \multicolumn{1}{c|}{$\boldsymbol{\beta}$} \\
\hline Relative humidity & \multicolumn{1}{c}{$\%$} & 2.190 & 0.084 & 26.14 & 0.000 & 0.217 \\
\hline Minimum temperature & ${ }^{\circ} \mathrm{C}$ & -0.068 & 0.003 & -21.18 & 0.000 & -0.215 \\
\hline Trail facility & Dummy & -0.872 & 0.054 & -16.11 & 0.000 & -0.131 \\
\hline Temperature $\geq \mathbf{2 0}^{\circ} \mathbf{C}$ & Dummy & 0.406 & 0.034 & 11.80 & 0.000 & 0.109 \\
\hline Wind speed & $\mathrm{km} / \mathrm{hr}$ & -0.021 & 0.002 & -10.80 & 0.000 & -0.099 \\
\hline Major road & Dummy & 0.236 & 0.020 & 11.64 & 0.000 & 0.097 \\
\hline Separated facility & Dummy & -0.171 & 0.021 & -7.96 & 0.000 & -0.067 \\
\hline Constant & & 6.681 & 0.082 & 81.74 & 0.000 & \\
\hline
\end{tabular}

Two other factors - the centerline roadway distance and the simulated daily volume-were also considered but ultimately omitted. In the case of the centerline distance, it was moderately co-linear with the trail facility; however, the latter had a slightly larger impact. The daily volume could not co-exist in the model with the major road dummy variable, and again the latter had a slightly larger impact. Yet this in itself tells us something more. These two variables were considerably difficult to procure, requiring either extensive GIS work or a region-wide mesoscopic simulation, respectively. To obtain the same results with much simpler, available information, this exercise will be easier to both comprehend and repeat.

\section{$5 \quad$ Conclusion and recommendations}

This research has contributed a number of interesting findings. In summary, multi-use trails showed the lowest concentrations for both pollutants. For both in-street and separated facilities, riding on or alongside a local street exposed cyclists to lower levels for both pollutants. Cyclists were not exposed to significantly different UFP concentrations on in-street and separated facilities; however, BC exposure was significantly lower on separated facilities. These results are mostly consistent with the mild reductions seen in pollution on separated facilities, and more notable reductions on streets with less traffic, seen in the existing literature. Yet in addition to these pollutants in particular, these measurements may serve as a surrogate for an assortment of other harmful pollutants that have been shown to be correlated 
with UFP and BC. For instance, there is growing interest in associations between $\mathrm{BC}$ and noise pollution. Research has in fact shown that audio frequency can be used in combination with meteorological and built environment metrics to provide an accurate and cost effective proxy to black carbon exposure across large spatial ranges (Dekoninck, Botteldooren, and Int Panis 2013). Ultimately, many pollutants are cross correlated and efforts to reduce exposure to those measured in this study will also likely benefit cyclists' wellbeing with respect to other pollutants as well.

There were a number of limitations in this study. For one, land-use characteristics not directly related to cycling facilities were beyond the scope of this paper, which sought to address specifically the effect of cycling infrastructure. The authors are aware of the importance of these factors, which will be the subject of future research. Furthermore previous research by this group has shown the importance of vehicle composition, in particular trucks, as a determinant of UFP and BC (Hatzopoulou et al. 2013, Weichenthal et al. 2014). Other limitations arise when analyzing such a large, aggregate dataset. Due to the high temporal variability and large spatial extent, many effects on pollutant concentrations necessarily went unobserved. For instance, the specific quantity and composition of traffic, as well as unobserved changes in meteorological conditions, can play a large role in instantaneous UFP and BC levels. Although amalgamating so many observations will inevitably mask this variability, the authors believe that the trends ultimately detected are subsequently more reliable.

One intent of the study was to determine whether spatially extensive snapshots of air pollution could provide useful information for land-use regression analysis; however, setting aside an instrument to monitor background pollution may help account for some of the daily fluctuations in air pollution. In addition to daily variation, air pollution concentrations can drastically change with season. Since this investigation was conducted exclusively in the summer, these seasonal variations could not be studied.

Although this research question is in need of more studies to draw more robust conclusions, a number of provisional recommendations can be drawn from the results of this particular exercise. With respect to designing comprehensive urban cycling networks, an effort to attract utilitarian cyclists to either low-volume streets, or better yet, park trails, could help in mitigating their exposure to UFP and BC. This should not be understood as a suggestion to design burdensome, indirect networks for cyclists. On the contrary, the authors suggest that access and convenience for cyclists on local streets be increased. For example, in the study area of Montreal, many local streets adjacent and parallel to major streets permit only one-way traffic, often switching directions every few blocks to prevent abusing the side-streets as thoroughfares. However, if contra-flow lanes were painted as necessary, or bicycle "salmoning" (riding in the opposite direction permitted to traffic) were sanctioned on these low-volume side-streets, cyclists may be exposed to lower concentrations of pollution. Though often reflexively dismissed as inherently unsafe, such an intervention has been recently shown to actually reduce risk of injury (Vandenbulcke, Thomas, and Int Panis 2014). Another possible intervention to facilitate cyclists' use of side-streets is to allow them to pass through diverters, which are typically used to force drivers to turn from a local street onto a major street.

Finally, it appears that at least for BC, separated facilities do provide mild benefits. It is unclear from this project whether these are due simply to the increased distance or rather the specific composition of the cycle track. Future research in this area could be to determine whether separation such as a row of parked cars between the traveled way and the cycle track reduce the BC exposure more than the distance alone. Furthermore, this effect was greater on major streets, implying that the presence of separated cycling infrastructure may be more critical for cyclist health on such roads.

As a final remark, the authors would like to make clear that despite the elevated risks of negative health outcomes pertaining to air pollution, the benefit of the physical activity required for cycling allows it to remain an overall healthier alternative to more sedentary modes of transport, even in light of 
risks posed by collisions and air pollution exposure (de Hartog et al. 2010, Rojas-Rueda et al. 2011, Rabl and de Nazelle 2012). So while it should be acknowledged that cycling remains an overall healthy activity, this ought not result in complacency with preventable risks, including the dangers of inhaling traffic-related air pollution, especially as cycling continues to be encouraged as a positive force for the environment and personal health.

\section{Acknowledgments}

The authors would like to thank the research assistants, some of whom cycled over 1000 kilometers in the course of this exercise, for their extraordinary data collection and compilation efforts: Noel Brownlie, Bernard Moulins, Julien Neves-Pelchat, Graeme Pickett, Rhokho Kim, Rebecca Luck, Nicolas Truong, and Mohamad Zukari. The authors also thank Timothy Sider for the use of vehicular volume results from the mesoscopic traffic simulation, an important contextual component of this study. Next, we thank the Transportation Research at McGill (TRAM) group for providing the bicycle network data. Finally, the authors thank the National Sciences and Engineering Research Council of Canada (NSERC) and the Canadian Institute of Health Research (CIHR) for their Collaborative Health Research Projects (CHRP) grant, which made this study possible.

\section{References}

Baldauf, R., E. Thoma, A. Khlystov, V. Isakov, G. Bowker, T. Long, and R. Snow. 2008. Impacts of noise barriers on near-road air quality. Atmospheric Environment 42 (32): 7502-7507. doi:10.1016/j.atmosenv.2008.05.051. URL: http://linkinghub.elsevier.com/retrieve/pii/ S1352231008005311.

Berghmans, P., N. Bleux, L. Int Panis, V. K. Mishra, R. Torfs, and M. Van Poppel. 2009. Exposure assessment of a cyclist to PM10 and ultrafine particles. The Science of the Total Environment 407(4): 1286-98. doi:10.1016/j.scitotenv.2008.10.041. URL: http://www.ncbi.nlm.nih.gov/ pubmed/19036413.

Boogaard, H., F. Borgman, J. Kamminga, and G. Hoek. 2009. Exposure to ultrafine and fine particles and noise during cycling and driving in 11 Dutch cities. Atmospheric Environment 43 (27): 4234-4242. doi:10.1016/j.atmosenv.2009.05.035. URL: http://linkinghub.elsevier.com/retrieve/ pii/S1352231009004506.

Briggs, D. J., K. de Hoogh, C. Morris, and J. Gulliver. 2008. Effects of travel mode on exposures to particulate air pollution. Environment International 34(1): 12-22. doi:10.1016/j.envint.2007.06.011. URL: http://www.ncbi.nlm.nih.gov/pubmed/17688949.

Brook, R. D., B. Franklin, W. Cascio, Y. Hong, G. Howard, M. Lipsett, R. Luepker, et al. 2004. Air pollution and cardiovascular disease: A statement for healthcare professionals from the expert panel on population and prevention science of the American Heart Association. Circulation 109(21): 2655-71. doi:10.1161/01.CIR.0000128587.30041.C8. URL: http:/www.ncbi.nlm.nih.gov/ pubmed/15173049.

Brunekreef, B., and S. T. Holgate. 2002. Air pollution and health. Lancet 360(9341): 1233-42. doi:10.1016/S0140-6736(02)11274-8. URL: http://www.ncbi.nlm.nih.gov/pubmed/12401268.

Buccolieri, R., C. Gromke, S. Di Sabatino, and B. Ruck. 2009. Aerodynamic effects of trees on pollutant concentration in street canyons. The Science of the Total Environment 407(19): 5247-56. doi:10.1016/j.scitotenv.2009.06.016. URL: http://www.ncbi.nlm.nih.gov/pubmed/19596394.

Calderón-Garcidueñas, L., A. C. Solt, C. Henríquez-Roldán, R. Torres-Jardón, B. Nuse, L. Herritt, R. Villarreal-Calderón, et al. 2008. Long-term air pollution exposure is associated with neuroin- 
flammation, an altered innate immune response, disruption of the blood-brain barrier, ultrafine particulate deposition, and accumulation of amyloid beta- 42 and alpha-synuclein in children and youth. Toxicologic Pathology 36: 289-310. doi:10.1177/0192623307313011. URL: http://www. ncbi.nlm.nih.gov/pubmed/18349428.

Card, J. W., D. C. Zeldin, J. C. Bonner, and E. R. Nestmann. 2008. Pulmonary applications and toxicity of engineered nanoparticles. American Journal of Physiology-Lung Cellular and Molecular Physiology 295(3): 400-411. doi:10.1152/ajplung.00041.2008.

Chen, H., M. S. Goldberg, and P. J. Villeneuve. 2008. A systematic review of relation between longterm exposure to ambient air pollution and chronic disease. Reviews on Environmental Health 23(4): 243-297. URL: http://www.ncbi.nlm.nih.gov/pubmed/19235364.

De Hartog, J. J., H. Boogaard, H. Nijland, and G. Hoek. 2010. Do the health benefits of cycling outweigh the risks? Environmental Health Perspectives 118(8): 1109-16. doi:10.1289/ehp.0901747.

URL: http://www.pubmedcentral.nih.gov/articlerender.fcgi?artid=2920084\&tool=pmcentrez\&ren dertype $=$ abstract.

De Nazelle, A., S. Fruin, D. Westerdahl, D. Martinez, A. Ripoll, N. Kubesch, and M. Nieuwenhuijsen. 2012. A travel mode comparison of commuters' exposures to air pollutants in Barcelona. Atmospheric Environment 59: 151-159. doi:10.1016/j.atmosenv.2012.05.013. URL: http://linkinghub.elsevier.com/retrieve/pii/S1352231012004621.

Dekoninck, L., D. Botteldooren, and L. Int Panis. 2013. An instantaneous spatiotemporal model to predict a bicyclist's black carbon exposure based on mobile noise measurements. Atmospheric Environment 79: 623-631. doi:10.1016/j.atmosenv.2013.06.054. URL: http://linkinghub.elsevier. $\mathrm{com} /$ retrieve/pii/S1352231013005190.

Dockery, D. W. 2001. Epidemiologic evidence of cardiovascular effects of particulate air pollution. Environmental Health Perspectives 109: 483-6. URL: http://www.pubmedcentral.nih.gov/articlerender.fcgi?artid $=1240569$ \& tool $=$ pmcentrez\&rendertype $=$ abstract.

Dons, E., L. Int Panis, M. Van Poppel, J. Theunis, and G. Wets. 2012. Personal exposure to black carbon in transport microenvironments. Atmospheric Environment 55: 392-398. doi:10.1016/j. atmosenv.2012.03.020. URL: http://linkinghub.elsevier.com/retrieve/pii/S1352231012002610.

Dons, E., P. Temmerman, M. Van Poppel, T. Bellemans, G. Wets, and L. Int Panis. 2013. Street characteristics and traffic factors determining road users' exposure to black carbon. The Science of the Total Environment 447: 72-9. doi:10.1016/j.scitotenv.2012.12.076. URL: http://www.ncbi.nlm. nih.gov/pubmed/23376518.

Frank, L. D., J. Kerr, J. F. Sallis, R. Miles, and J. Chapman. 2008. A hierarchy of sociodemographic and environmental correlates of walking and obesity. Preventive Medicine 47(2): 172-8. doi:10.1016/j.ypmed.2008.04.004. URL: http://www.ncbi.nlm.nih.gov/pubmed/18565576.

Frank, L. D., B. E. Saelens, K. E. Powell, and J. E. Chapman. 2007. Stepping towards causation: Do built environments or neighborhood and travel preferences explain physical activity, driving, and obesity? Social Science and Medicine 65(9): 1898-914. doi:10.1016/j.socscimed.2007.05.053. URL: http://www.ncbi.nlm.nih.gov/pubmed/17644231.

Greaves, S., T. Issarayangyun, and Q. Liu. 2008. Exploring variability in pedestrian exposure to fine particulates (PM2.5) along a busy road. Atmospheric Environment 42(8): 1665-1676. doi:10.1016/j.atmosenv.2007.11.043. URL: http://linkinghub.elsevier.com/retrieve/pii/ S1352231007010886.

Hagler, G. S.W. 2011. Post-processing method to reduce noise while preserving high time resolution in aethalometer real-time black carbon data. Aerosol and Air Quality Research 11(5): 539-546. doi:10.4209/aaqr.2011.05.0055. URL: http://www.aaqr.org/Doi.php?id=8_AAQR-11-05-OA- 
$0055 \& v=11 \& \mathrm{i}=5 \& \mathrm{~m}=10 \& \mathrm{y}=2011$.

Hatzopoulou, M., S. Weichenthal, H. Dugum, G. Pickett, L. Miranda-Moreno, R. Kulka, R. Andersen, and M. Goldberg. 2013. The impact of traffic volume, composition, and road geometry on personal air pollution exposures among cyclists in montreal, Canada. Journal of Exposure Science and Environmental Epidemiology 23(1): 46-51. doi:10.1038/jes.2012.85. http://www.ncbi.nlm. nih.gov/pubmed/22910003.

Highwood, E. J, and R. P. Kinnersley. 2006. When smoke gets in our eyes: The multiple impacts of atmospheric black carbon on climate, air quality and health. Environment International 32(4): 560 6. doi:10.1016/j.envint.2005.12.003. URL: http://www.ncbi.nlm.nih.gov/pubmed/16513170. Int Panis, L., B. de Geus, G. Vandenbulcke, H. Willems, B. Degraeuwe, N. Bleux, V. Mishra, I. Thomas, and R. Meeusen. 2010. Exposure to particulate matter in traffic: A comparison of cyclists and car passengers. Atmospheric Environment 44(19): 2263-2270. doi:10.1016/j.atmosenv.2010.04.028. URL: http://linkinghub.elsevier.com/retrieve/pii/S1352231010003225.

Jacobs, L., T. S. Nawrot, B. de Geus, R. Meeusen, B. Degraeuwe, A. Bernard, M. Sughis, B. Nemery, and L. Int Panis. 2010. Subclinical responses in healthy cyclists briefly exposed to traffic-related air pollution: An intervention study. Environmental Health 9(64): 1-8. doi:10.1186/1476-069X-9-64. URL: http://www.pubmedcentral.nih.gov/articlerender.fcgi?artid=2984475\&tool=pmcentrez\&ren dertype $=$ abstract.

Jansen, K. L., T. V. Larson, J. Q. Koenig, T. F. Mar, C. Fields, J. Stewart, and M. Lippmann. 2005. Associations between health effects and particulate matter and black carbon in subjects with respiratory disease. Environmental Health Perspectives 113(12): 1741-1746. doi:10.1289/ehp.8153. URL: http://www.ehponline.org/ambra-doi-resolver/10.1289/ehp.8153.

Katsouyanni, K., G. Touloumi, E. Samoli, A. Gryparis, A. Le Tertre, Y. Monopolis, G. Rossi, D. Zmirou, F. Ballester, A. Boumghar, H. R. Anderson, B. Wojtyniak, A. Paldy, R. Braunstein, J. Pekkanen, C. Schindler, J. Schwartz. 2001. Confounding and effect modification in the short-term effects of ambient particles on total mortality: Results from 29 European cities within the APHEA2 project. Epidemiology 12(5): 521-31. URL: http://www.ncbi.nlm.nih.gov/ pubmed/11505171.

Kaur, S., and M. J. Nieuwenhuijsen. 2009. Determinants of personal exposure to PM2.5, ultrafine particle counts, and CO in a transport microenvironment. Environmental Science and Technology 43(13): 4737-43. URL: http://www.ncbi.nlm.nih.gov/pubmed/19673259.

Kaur, S., M. Nieuwenhuijsen, and R. Colvile. 2005. Personal exposure of street canyon intersection users to PM2.5, ultrafine particle counts and carbon monoxide in central London, UK. Atmospheric Environment 39(20): 3629-3641. doi:10.1016/j.atmosenv.2005.02.046. URL: http://linkinghub.elsevier.com/retrieve/pii/S1352231005002268.

Kaur, S., M. J. Nieuwenhuijsen, and R. N. Colvile. 2007. Fine particulate matter and carbon monoxide exposure concentrations in urban street transport microenvironments. Atmospheric Environment 41 (23): 4781-4810. doi:10.1016/j.atmosenv.2007.02.002. URL: http://linkinghub.elsevier. $\mathrm{com} /$ retrieve/pii/S1352231007001343.

King, E. A., E. Murphy, and A. McNabola. 2009. Reducing pedestrian exposure to environmental pollutants: A combined noise exposure and air quality analysis approach. Transportation Research Part D: Transport and Environment 14(5): 309-316. doi:10.1016/j.trd.2009.03.005. URL: http:// linkinghub.elsevier.com/retrieve/pii/S1361920909000364.

Kingham, S., I. Longley, J. Salmond, W. Pattinson, and K. Shrestha. 2013. Variations in exposure to traffic pollution while traveling by different modes in a low density, less congested city. Environmental Pollution 181: 211-218. doi:10.1016/j.envpol.2013.06.030. URL: http://www.ncbi.nlm. 
nih.gov/pubmed/23871818.

Li, N., C. Sioutas, A. Cho, D. Schmitz, C. Misra, J. Sempf, M. Wang, T. Oberley, J. Froines, and A. Nel. 2002. Ultrafine particulate pollutants induce oxidative stress and mitochondrial damage. Environmental Health Perspectives 111(4): 455-460. doi:10.1289/ehp.6000. http://www.ehponline. org/ambra-doi-resolver/10.1289/ehp.6000.

Martins, L. D., J. A. Martins, E. D. Freitas, C. R. Mazzoli, F. L. T. Gonçalves, R. Y. Ynoue, R. Hallak, T. T. Albuquerque, and M. De Fatima Andrade. 2010. Potential health impact of ultrafine particles under clean and polluted urban atmospheric conditions: A model-based study. Air Quality, Atmosphere, and Health 3(1): 29-39. doi:10.1007/s11869-009-0048-9. URL: http://www.pubmedcentral.nih.gov/articlerender.fcgi?artid=2844959\&tool=pmcentrez\&rendertype=abstract.

McNabola, A., B. M. Broderick, and L. W. Gill. 2008. Reduced exposure to air pollution on the boardwalk in Dublin, Ireland. Measurement and prediction. Environment International 34(1): 8693. doi:10.1016/j.envint.2007.07.006. URL: http://www.ncbi.nlm.nih.gov/pubmed/17868869.

Pope, C. Arden. 2000. Epidemiology of fine particulate air pollution and human health: Biologic mechanisms and who's at risk? Environmental Health Perspectives 108: 713-23. URL: http://www. pubmedcentral.nih.gov/articlerender.fcgi?artid=1637679\&tool=pmcentrez\&rendertype=abstract.

Pope, C. A., and D. W. Dockery. 2006. Health effects of fine particulate air pollution: Lines that connect. Journal of the Air and Waste Management Association 56(6): 709-742. doi:10.1080/10473289 .2006.10464485. URL: http://www.tandfonline.com/doi/abs/10.1080/10473289.2006.1046448 5.

Rabl, A., and A. de Nazelle. 2012. Benefits of shift from car to active transport. Transport Policy 19(1): 121-131. doi:10.1016/j.tranpol.2011.09.008. URL: http://linkinghub.elsevier.com/retrieve/pii/ S0967070X11001119.

Rojas-Rueda, D., A. de Nazelle, M. Tainio, and M. J. Niewuwenhuijsen. 2011. The health risks and benefits of cycling in urban environments compared with car use: Health impact assessment study. British Medical Journal 343: 1-8. doi:10.1136/bmj.d4521. URL: http:/www.ncbi.nlm.nih.gov/ pmc/articles/PMC3150633/.

Samet, J. M., F. Dominici, F. C. Curriero, I. Coursac, and S. L. Zeger. 2000. Fine particulate air pollution and mortality in 20 US cities, 1987-1994. New England Journal 343(24): 1742-1749. URL: http://www.nejm.org/doi/full/10.1056/NEJM200012143432401.

Sider, T., A. Alam, M. Zukari, H. Dugum, N. Goldstein, N. Eluru, and M. Hatzopoulou. 2013. Land-use and aocio-economics as determinants of traffic emissions and individual exposure to air pollution. Journal of Transport Geography 33: 230-239. doi:10.1016/j.jtrangeo.2013.08.006. URL: http://linkinghub.elsevier.com/retrieve/pii/S0966692313001555.

Strak, M., H. Boogaard, K. Meliefste, M. Oldenwening, M. Zuurbier, B. Brunekreef, and G. Hoek. 2010. Respiratory health effects of ultrafine and fine particle exposure in cyclists. Occupational and Environmental Medicine 67(2): 118-24. doi:10.1136/oem.2009.046847. URL: http://www.ncbi. nlm.nih.gov/pubmed/19773283.

Strauss, J., L. Miranda-Moreno, D. Crouse, M. S. Goldberg, N. A. Ross, and M. Hatzopoulou. 2012. Investigating the link between cyclist volumes and air pollution along bicycle facilities in a dense urban core. Transportation Research Part D: Transport and Environment 17(8): 619-625. doi:10.1016/j.trd.2012.07.007. URL: http://linkinghub.elsevier.com/retrieve/pii/ S1361920912000806.

Tsai, D.-H., Y.-H. Wu, and C.-C. Chan. 2008. Comparisons of commuter's exposure to particulate matters while using different transportation modes. The Science of the Total Environment 405(1-3): 71-7. doi:10.1016/j.scitotenv.2008.06.016. URL: http://www.ncbi.nlm.nih.gov/ 
pubmed/18657850.

Vandenbulcke, G., I. Thomas, and L. Int Panis. 2014. Predicting cycling accident risk in Brussels: A spatial case-control approach. Accident; Analysis and Prevention 62: 341-57. doi:10.1016/j. aap.2013.07.001. URL: http://www.ncbi.nlm.nih.gov/pubmed/23962661.

Wang, Y., P. K. Hopke, D. C. Chalupa, and M. J. Utell. 2011. Long-term study of urban ultrafine particles and other pollutants. Atmospheric Environment 45(40): 7672-7680. doi:10.1016/j. atmosenv.2010.08.022. URL: http://linkinghub.elsevier.com/retrieve/pii/S1352231010006965.

Weichenthal, S., W. Farrell, M. Goldberg, L. Joseph, and M. Hatzopoulou. 2014. Characterizing the impact of traffic and the built environment on near-road ultrafine particle and black carbon concentrations. Environmental Research 132: 305-10. doi:10.1016/j.envres.2014.04.007.

URL: http://www.ncbi.nlm.nih.gov/pubmed/24834826.

Weichenthal, S., R. Kulka, A. Dubeau, C. Martin, D. Wang, and R. Dales. 2011. Traffic-related air pollution and acute changes in heart rate variability and respiratory function in urban cyclists. Environmental Health Perspectives 119(10): 1373-8. doi:10.1289/ehp.1003321. URL: http://www. pubmedcentral.nih.gov/articlerender.fcgi?artid=3230442\&tool=pmcentrez\&rendertype=abstract. Zuurbier, M., G. Hoek, M. Oldenwening, K. Meliefste, P. van den Hazel, and B. Brunekreef. 2011. Respiratory effects of commuters' exposure to air pollution in traffic. Epidemiology 22(2): 219-27. doi:10.1097/EDE.0b013e3182093693. URL: http://www.ncbi.nlm.nih.gov/pubmed/21228698. 